\title{
Removal of Dyes from Textile Wastewater Using Sawdust as Low-cost Biosorbent
}

\author{
ANDREEA BONDAREV ${ }^{1 *}$, CATALINA-GABRIELA GHEORGHE ${ }^{1}$, VIOREL GHEORGHE ${ }^{1}$, \\ MIHAELA BOMBOS ${ }^{2}$ \\ ${ }^{1}$ Petroleum-Gas University of Ploiesti, Romania, Chemistry Department, 39 Bucuresti Blvd., 100680, Ploiesti, Romania \\ ${ }^{2}$ The National Institute for Research \& Development in Chemistry and Petrochemistry, 202 Splaiul Independentei 060021, \\ Bucharest, Romania
}

\begin{abstract}
Dyes removal from textile effluents has been a matter of concern, both in health point of view and in the aesthetic sense. A waste material, characterized by ligno cellulose composition, availability and low cost was tested for its ability to remove synthetic dyes from aqueous systems. This study presents the results of the adsorption process of Alizarin Red $S(A R)$ on some adsorbents: white pine sawdust (Pinus durangensis) and beech wood sawdust (Fagus sylvatica). The suitability of the Langmuir, Freundlich and Harkins - Jura adsorption models to the equilibrium data were investigated for each reactive dye - adsorbent system, in order to establish all favourable conditions to uptake of $A R$ reactive dye from aqueous solution. The results of this study indicate that waste of wood is an attractive sorbent for removing synthetic dyes from the wastewater.
\end{abstract}

Keywords: adsorption, sawdust, removal, synthetic dyes

\section{Introduction}

The presence of rective dyes in the environment can generate serious problems because their possible toxicity. Due to their aromatic structures, these compounds are stable, no biodegradable and difficult to remove from the industrial effluents before their discharges into different emissaries [1].

Several technologies have been developed to remove synthetic dyes from industrial effluents: chemical precipitation, membrane filtration, coagulation/flocculation process, ion exchange, oxidation process, adsorption, reverse osmosis, solvent extraction [1-3]. Extensive research has been conducted to develop innovative and low cost adsorbent materials to deal with problem of wastewater contamination [2].

Adsorption is an efficient and economic method for reactive dyes removal. One of the advantages is the possibility to use a large variety of synthetic and natural low-cost materials. [3] In the past several decades, the overall attention was moved to the non-conventional and low-cost materials which include agricultural and industrial by-products and wastes.[1-3] Literature studies reported that biosorption could reduce $20 \%$ - $36 \%$ of capital, operational and total cost in comparison with conventional systems, respectively [4]. The uptake capacity of biomaterials can be enhanced by physical and chemical modifications with inorganic and organic activants (e.g. $\mathrm{HCl}, \mathrm{H}_{3} \mathrm{PO}_{4}, \mathrm{HNO}_{3}$, $\mathrm{NaOH}, \mathrm{CH}_{3} \mathrm{OH}$, acetone, etc.) [4].

Physical and chemical characteristics of biosorbents are very important to understand potential application of these materials and adsorption mechanism [3,4]. For example, wooden materials, coconut shell, pineapple leaves, sugar cane bagasse, coffee waste have the highest cellulose contents $(>40 \%)$. The highest lignin content (>30\%) appears in biomass like soft wood, bark and coconut shell. [4]An important factor for binding organic pollutants on lignocellulose is the existence of functional groups such as hydroxyl $(-\mathrm{OH})$, carboxyl $(-\mathrm{COOH})$ and aromatic rings, ketone, aldehydes, which are responsible for sorption of organic pollutants from the aquatic environment $[4,5]$.

\footnotetext{
*email: andreeabondarev@yahoo.com,
} 
According to the classification of pores suggested by the IUPAC, the wood sawdust can be considered a mesoporous material since the average pore diameter was within 2 and $50 \mathrm{~nm}$ [6-8].

The sorption of synthetic dyes on solid materials based on wood wastes have been intensively studied $[2,3]$. Wood sawdust is a promising natural low-cost material for the treatment of polluted wastewater containing cationic dyes, since it has a high adsorption capacity compared with other agroindustrial wastes. It is well documented that the adsorption capacity of sawdust is significantly dependent on the species of wood $[3,4]$. The objective of this study was to elucidate the biosorption mechanism of AR on white pine sawdust (Pinus durangensis) and beech wood sawdust (Fagus sylvatica).

Alizarin Red S, an anthraquinone derivative, may be used for the staining of calcium containing osteocytes in differentiated culture of both human and rodent mesenchymal stem cells (MSCs). It is also used to study carbohydrate-boronic acid interactions [5] Alizarin Red S (AR) is also widely used in textile industry and due its biological, thermal and optical stability, the effluents of industry contains amounts of this dye. Alizarin Red $\mathrm{S}$ is an anthraquinone dye and it cannot be degraded naturally, due to the structures of aromatic rings and hence its turns to be a potential toxic to the aquatic life [6].

The biosorption mechanism will enable understanding the dependence of the adsorption capacity on the operating conditions and improving the removal of AR by biosorption on sawdust.

The suitability of the Langmuir, Freundlich and Harkins - Jura adsorption models to the equilibrium data were investigated for each reactive dye - adsorbent system, in order to establish all favourable conditions to uptake of AR reactive dye from aqueous solution.

\section{Material and methods Sorbent}

The experimental material comprised two common species wood white pine sawdust (Pinus durangensis) and beech wood sawdust (Fagus sylvatica) as a hardwood species. The size of wood sawdust ranged from 0.5 to $1.0 \mathrm{~mm}$.

Wood sawdust dried in an oven for $24 \mathrm{~h}$ at a temperature of $80^{\circ} \mathrm{C}$ was treated at room temperature with the aqueous solution of $\mathrm{NaOH} 1 \mathrm{~N}$ for $1 \mathrm{~h}$. The material activated in this way was rinsed with distilled water to neutralize excess of sodium hydroxide. Adsorbent supports were oven dried for $6 \mathrm{~h}$ at a temperature of ${ }^{\circ} \mathrm{C}$, then they were ground and sieved, to get homogenous particle sized material.

\section{Adsorbate:}

Alizarin Red S (AR): 3,4-Dihydroxy-9,10-dioxo-2-anthracenesulfonic acid sodium salt (Figure 1) was received from Sigma-Aldrich Chemicals and used without further purification.

Concentrations of dyes were determined by finding out the absorbance at the characteristic wavelength using a UV-Visible spectrophotometer UV-VIS CECIL CE 1011.

A stock solution of AR $(1000 \mathrm{mg} / \mathrm{L})$ was prepared by dissolving $1.0000 \mathrm{~g}$ of the dye in $1 \mathrm{~L}$ of distilled water. The standard solutions of AR were prepared by serial dilution of the stock solution. Calibration curves were plotted between absorbance and concentration of the dye solution.

The contents of each flask were filtered through Whatman 42 blue band filter paper and the filtrate was analyzed for dye concentration using UV-VIS spectrophotometry; this dye has $\lambda_{\max }$ at $420 \mathrm{~nm}$.

The $p \mathrm{H}$ was adjusted using $0.1 \mathrm{~N} \mathrm{HCl}$ and $0.1 \mathrm{~N} \mathrm{NaOH}$ solutions by using a CYBERSCAN PCD $6500 p \mathrm{H}$-meter with a combined $p \mathrm{H}$ electrode. Final $p \mathrm{H}$ of the sorbate-sorbent adsorption system was measured at sorption equilibrium. 
<smiles>O=C1c2ccccc2C(=O)c2c1cc(S(=O)(=O)O)c(O)c2O</smiles>

Figure 1. Molecular structure of Alizarin Red S (AR)

The influence of $p \mathrm{H}$, sorbent dosage, initial concentration of the dye and temperature on the removal of the dye with the waste of wood was studied.

\section{Spectroscopic study}

FTIR data of adsorbent materials are presented in the Figure 2,3.

The absorption bands observed in the range from 1500 to $1600 \mathrm{~cm}^{-1}$ can be associated with the characteristic vibrations of aromatic rings present in the structure of lignin.

The pronounced band at $1020 \mathrm{~cm}^{-1}$ and the attenuated absorption band at $1262 \mathrm{~cm}^{-1}$ correspond to the $\mathrm{C}-\mathrm{O}$ group, which is characteristic of alcohols, esters and carboxylic acids; all of them are present in the molecular structures of the principal components of sawdust.

The carbonyl groups $(\mathrm{C}=\mathrm{O})$ exhibited a characteristic band at $1710 \mathrm{~cm}^{-1}$ and were present in various types of hemicellulose. The band observed at $2916 \mathrm{~cm}^{-1}$ corresponded to the $\mathrm{C}-\mathrm{H}$ group, owing to cellulose, hemicellulose and lignin. The band at $3350 \mathrm{~cm}^{-1}$ was due to the $\mathrm{O}-\mathrm{H}$ groups mostly present in the cellulose. [7].

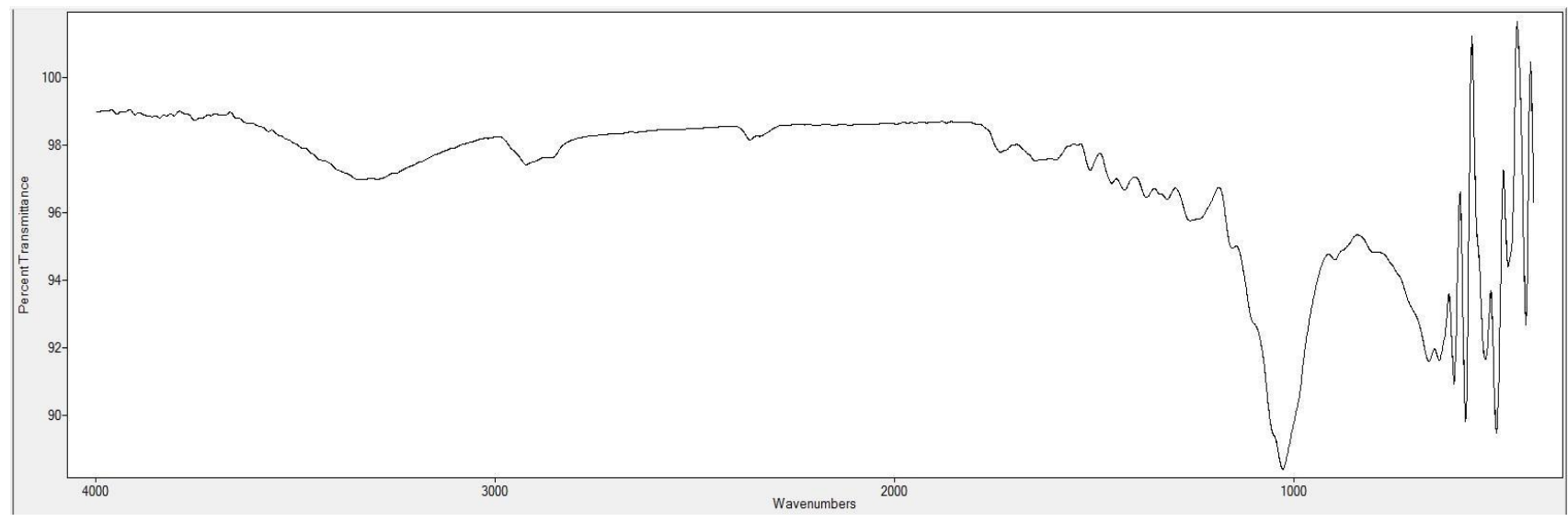

Figure 2. FTIR spectrum of beech wood sawdust (Fagus sylvatica)

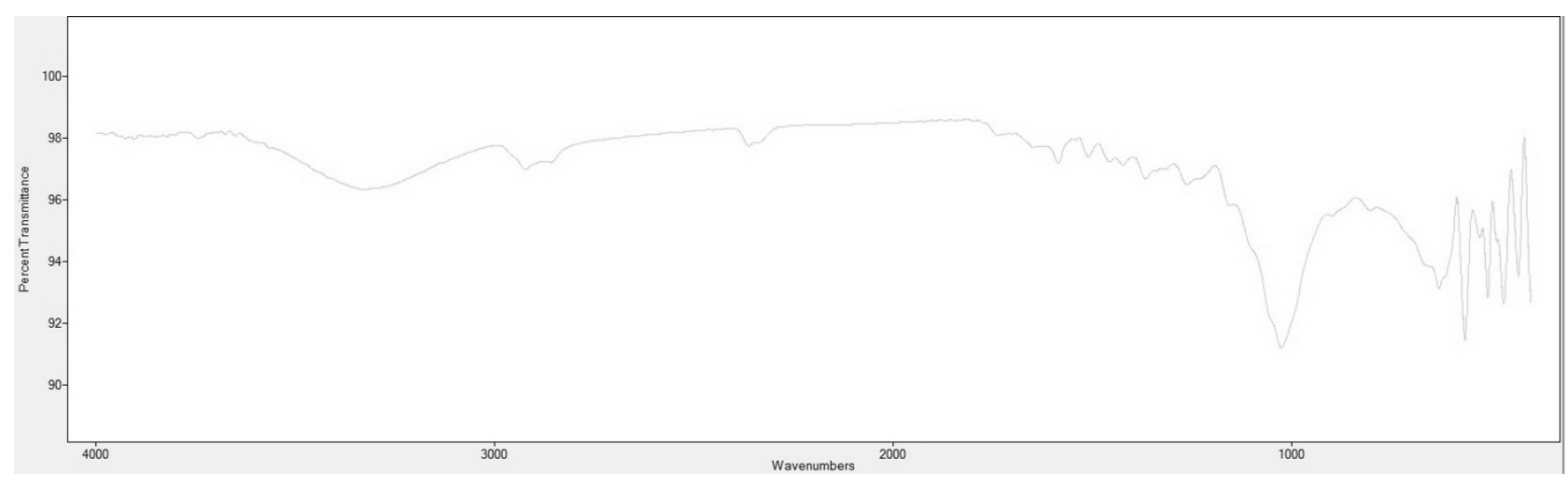

Figure 3. FTIR spectrum of wood white pine sawdust (Pinus durangensis) 


\section{Equilibrium studies}

Adsorption isotherm indicates how the adsorbate molecules interact with adsorbent and attains equilibrium.[9] The adsorption capacity of an adsorbent can be described by equilibrium sorption isotherm, which is characterized by definite constants whose values express the surface properties and affinity of an adsorbent support. [8]

The mass of AR adsorbed on sawdust $\left(q_{\mathrm{e}}, \mathrm{mg} / \mathrm{g}\right)$ was calculated by a mass balance of AR and the equation representing this mass balance is the following:[4]

$$
q_{e}=\left(C_{0}-C_{e}\right) \frac{V}{W}
$$

where $C_{0}(\mathrm{mg} / \mathrm{L})$ is the initial concentration of dye, $C_{e}(\mathrm{mg} / \mathrm{L})$ is the final dye concentration, $V$ is the volume of the solution (L) and $W$ is the mass of adsorbate $(\mathrm{g})$.

The percent removal of dye from solution $(\mathrm{R} \%)$ was calculated by the following equation: [4]

$$
\% R=\frac{C 0-\mathrm{Ce}}{\mathrm{CO}} \times 100
$$

where $C_{0}(\mathrm{mg} / \mathrm{L})$ is the initial concentration of dye, $C_{e}(\mathrm{mg} / \mathrm{L})$ is the residual dye concentration.

The equilibrium adsorption data was described in this study by Freundlich, Langmuir and HarkinsJura isotherm. [4-10]

The Freundlich isotherm is an empirical equation suitable to describe heterogeneous systems. This model can be applied for non-ideal adsorption on heterogeneous surfaces and multilayer sorption. The Freundlich model is commonly described as follow (Freundlich, 1906): [4-10]

$$
\begin{array}{ll}
q=K_{F} \times C^{1 / n} & \text { (2) original form; } \\
\lg q=\lg K_{F}+\frac{1}{n} \lg c & \text { (3) linearized form }
\end{array}
$$

where $K_{\mathrm{F}}\left(\mathrm{mg} \mathrm{g}^{-1}\right)$ and $\mathrm{n}$ (value between 0 and 1$)$ are Freundlich equilibrium constants, $C_{\mathrm{e}}$ is the equilibrium concentration of the solute in the bulk $(\mathrm{mg} / \mathrm{L})$ and $1 / \mathrm{n}$ is an empirical parameter relating the adsorption intensity, which varies with the heterogeneity of the material.

The Langmuir model is based on the assumption that adsorption occurs at specific equal sites within the adsorbent and and is used in many monolayer adsorption processes. This model is described as follow (Langmuir, 1918): [4-10]

$$
\begin{array}{ll}
q=\frac{q_{m \cdot K_{L} \cdot C}}{1+K_{L} C} & \text { (4) original form; } \\
\frac{\odot}{q}=\frac{1}{K_{L} q_{m}}+\frac{c}{q_{m}} & \text { (5) linearized form }
\end{array}
$$

where $q$ is the amount of dye adsorbed per specific amount of adsorbent $\left(\mathrm{mg} \mathrm{g}^{-1}\right), C_{\text {eq }}$ is equilibrium concentration $\left(\mathrm{mg} \mathrm{L}^{-1}\right.$ or $\left.\mathrm{mmol} \mathrm{L}^{-1}\right), q_{\mathrm{m}}$ is the monolayer adsorption capacity $\left(\mathrm{mg} \mathrm{g}^{-1}\right), K_{\mathrm{L}}$ is Langmuir equilibrium constant related to the energy of adsorption $\left(\mathrm{L} \mathrm{mg}^{-1}\right.$ or $\left.\mathrm{L} \mathrm{mmol}^{-1}\right)$.

It is reported that Harkins-Jura isotherm model mainly describes the multilayer adsorption and the existence of the heterogeneous pore distribution in the surface of adsorbents, which can be expressed as $B_{\mathrm{HJ}}$ and $A_{\mathrm{HJ}}$, the Harkins-Jura constants. [9-16]

$$
1 / \mathrm{q}^{2}=\left[\mathrm{B}_{H J} / \mathrm{A}_{H J}\right]-\left[1 / \mathrm{A}_{H J}\right] \log \mathrm{C}_{\mathrm{e}}
$$

$\mathrm{A}_{H J}$ is Harkins-Jura isotherm parameter which accounts for multilayer adsorption and explains the existence of heterogeneous pore distribution, while $\mathrm{B}_{H J}$ is the isotherm constants.[9] 


\section{Results and discussions}

\section{Effect of operating parameters}

\section{Effect of initial concentration}

Initial concentration is one of the parameters which have a pronounced effect on the removal of adsorbate species from aqueous solution (Figure 4).

The effect of the initial AR concentration on the adsorption rate was investigated in the range 20 $120 \mathrm{mg} / \mathrm{L}$. The adsorption experiments were carried out at room temperature i.e. $22 \pm 2{ }^{\circ} \mathrm{C}$, the adsorbent amount was of $0,4 \mathrm{~g}$ and contact time $1 \mathrm{~h}$, using ORBITAL SHAKER INCUBATOR, at $150 \mathrm{rot} / \mathrm{min}$.

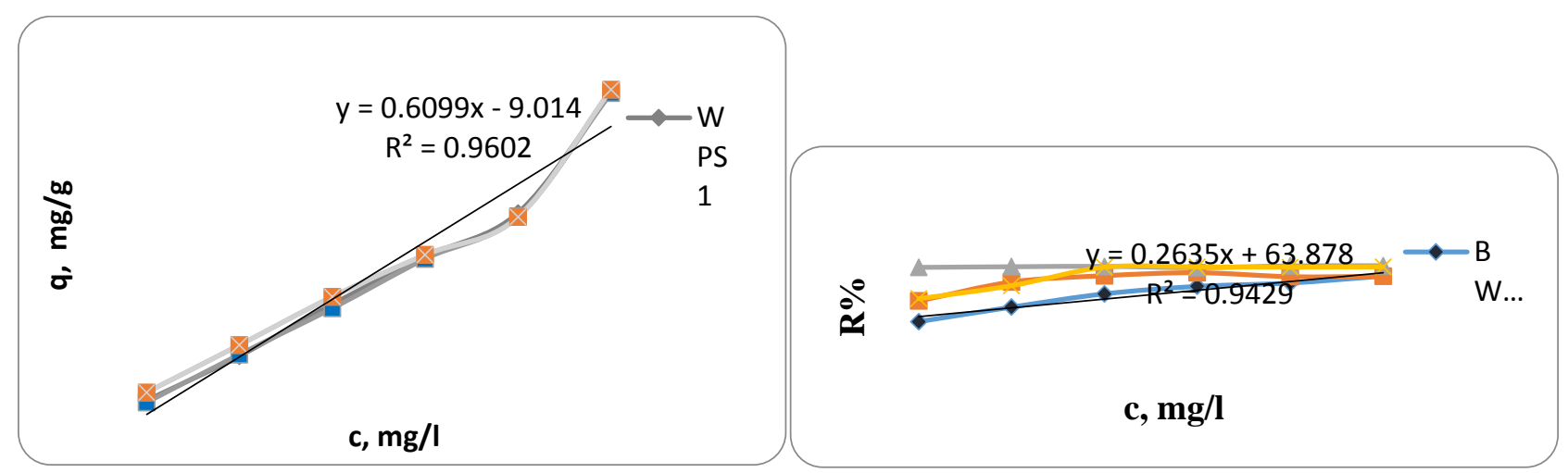

Figure 4. Effect of initial concentration of AR on the adsorbent materials (WPS1, WPS2, BWS1 and BWS2)

The uptake mechanism is dependent on the initial dye concentration: at low concentrations, it is adsorbed by specific sites; increasing concentrations, the specific sites are saturated and the exchange sites are filled. [4] Also, the figure 4 indicates that WPS1 had the best percentage removal (R\%).

\section{Effect of adsorbent dosage}

Adsorbent amount is an important parameter in the determination of adsorption capacity [10,11].

Figure 5 shows the adsorption of dyes as a function of adsorbent dosage. By increasing the adsorbent dose the amount of adsorbed dye increases, but adsorption density, the amount adsorbed per unit mass, decreases. The number of available adsorption sites increases by increasing the adsorbent dose [12]. The decrease in adsorption density with an increase in the adsorbent dose is mainly because of adsorption sites remain unsaturated during the adsorption reaction, whereas the number of sites available for adsorption site increases by increasing the adsorbent dose [12, 13].

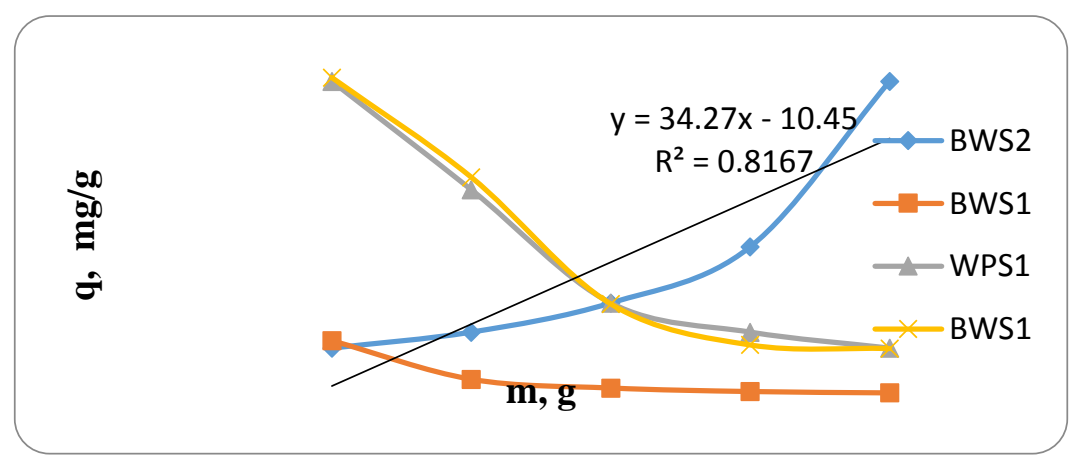

Figure 5. Effect of adsorbent dose on the adsorption of AR using different materials (WPS1, WPS2, BWS1 and BWS2) 


\section{Effect of pH}

The effect of $p \mathrm{H}$ on the rate of dye removal was analyzed in the $p \mathrm{H}$ range at 3, 5, 7 and 9 at $20{ }^{\circ} \mathrm{C}$, $150 \mathrm{rpm}$ and $100 \mathrm{~mL}$ of dye concentration $100 \mathrm{mg} / \mathrm{L}$ (Figure 6).

The $p \mathrm{H}$ was adjusted using $0.1 \mathrm{~N} \mathrm{NaOH}$ and $0.1 \mathrm{~N} \mathrm{HCl}$ solutions by using an CYBERSCAN PCD $6500 \mathrm{pH}$-meter. $\mathrm{pH}$-meter was standardized with NBS buffers before every measurement.

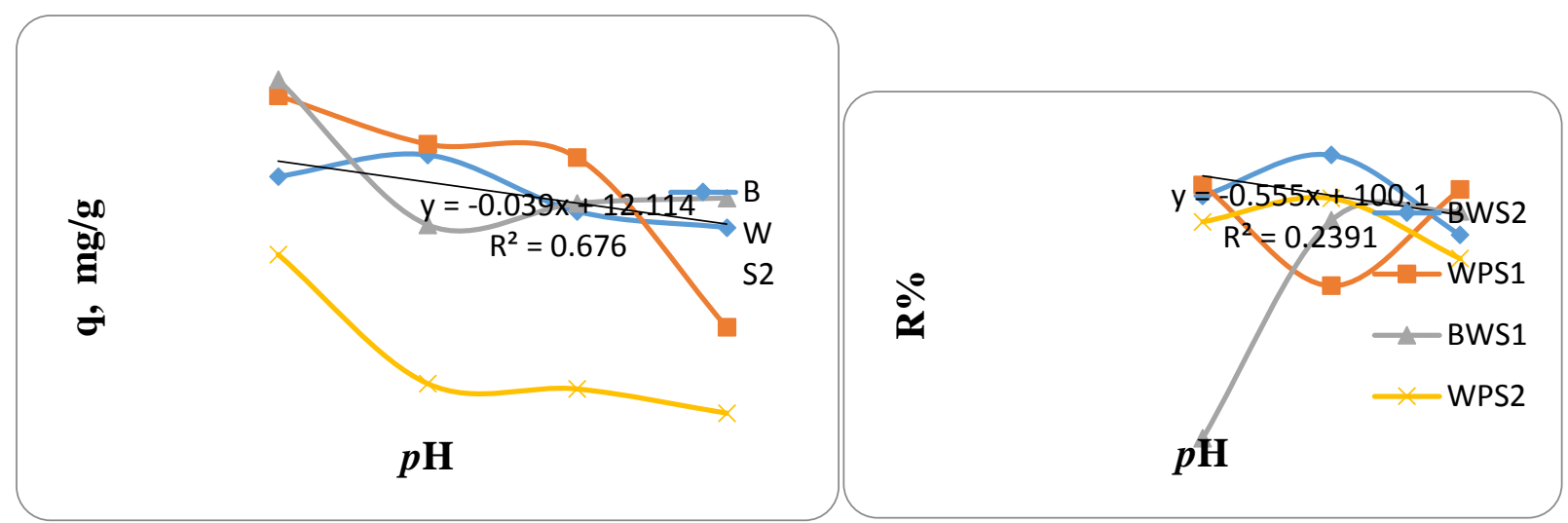

Figure 6. Effect of $p \mathrm{H}$ on the adsorption of AR using different materials (WPS1, WPS2, BWS1 and BWS2)

As the $p \mathrm{H}$ of the solution increases, adsorption of dyes was found to be decreasing. This was due to the extinction of the positive hydrogen ions thereby promoting activities of electrostatic repulsion between the negative charges of both dye and the adsorbent surface [11- 13].

\section{Effect of temperature}

The system was studied at three different temperatures, namely 30,45 and $60^{\circ} \mathrm{C}$, using $0.6 \mathrm{~g}$ of adsorbent in contact with $100 \mathrm{~mL}$ of $100 \mathrm{mg} / \mathrm{L} \mathrm{AR}$ solution, agitated at $150 \mathrm{rpm}$.

It is clear that adsorption capacity of adsorbent increases as the temperature increases, due to increase in the mobility of dye ions increasing temperature also causes a swelling effect within the internal structure of adsorbent (Figure 7); large number of dye molecules can easily penetrate through it. [14] Similar results for dyes and other biosorbents have also been reported in literatures [12-15].

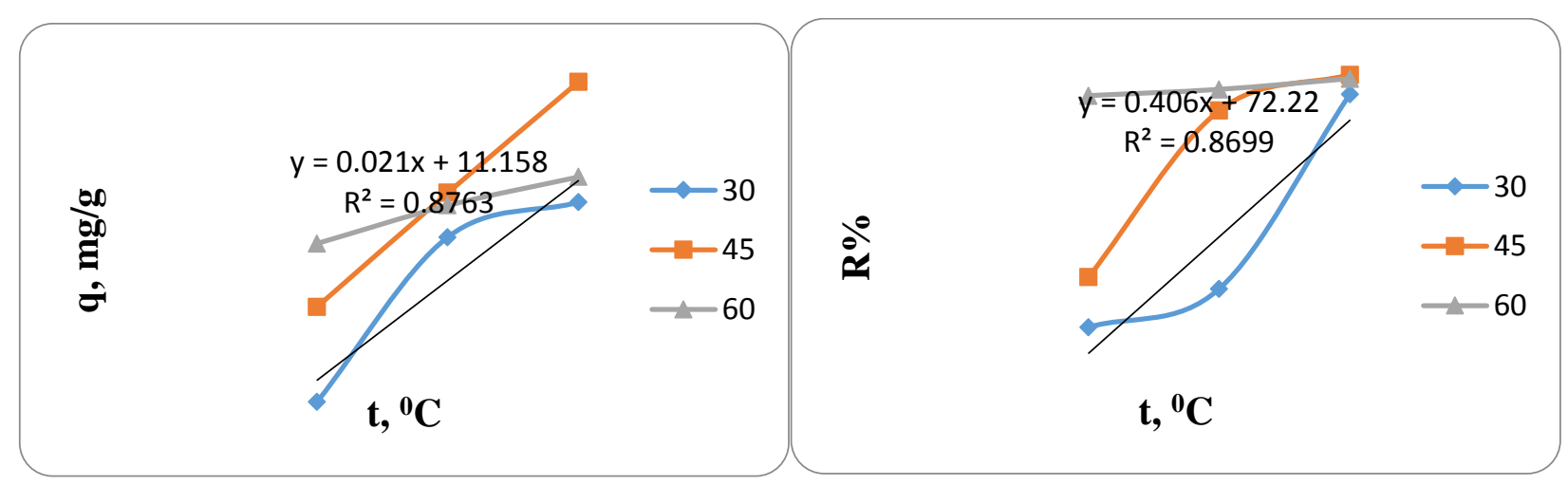

Figure 7. Effect of temperature on the adsorption of AR using wood white pine sawdust (WPS2) 


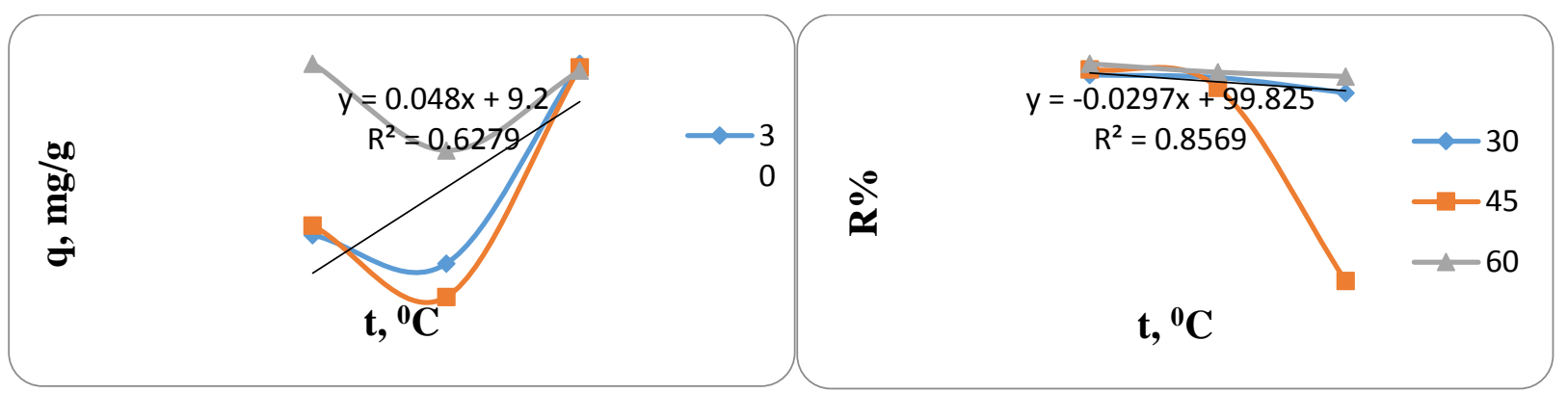

Figure 8. Effect of temperature on the adsorption of AR using beech wood sawdust (BWS2)

\section{Adsorption isotherm models}

Equilibrium adsorption data were used to determine the maximum capacities of the adsorbents during the experiment. The adsorption isotherm can describe the distribution of dye between solid phase and the solution at a certain temperature, when the equilibrium was reached.

The linearized Langmuir and Freundlich isotherms of AR are shown in Fig. 9-13.

The adsorption intensities and adsorption capacities $\left(\mathrm{q}_{\mathrm{m}}\right)$ were determined from the intercept and slope data, respectively, for each adsorbent (fig.9,10,11).

Harkin Jura constants A, B were calculated from slope and intercept of this plot (fig.12,13).

The isotherm models were expressed by relative certain constants which characterized the surface properties and indicated adsorption capacity of each material.

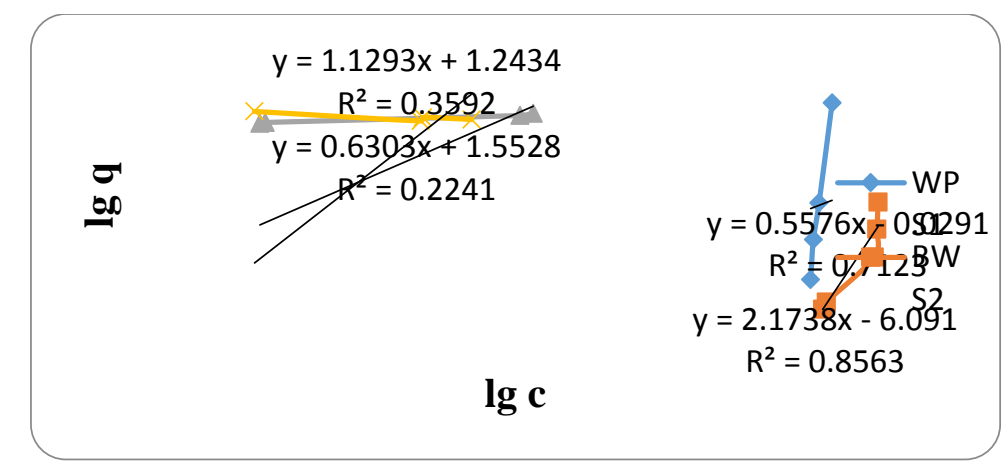

Figure 9. Freundlich isotherms plot for AR using different adsorbents (WPS1, WPS2, BWS1 and BWS2)

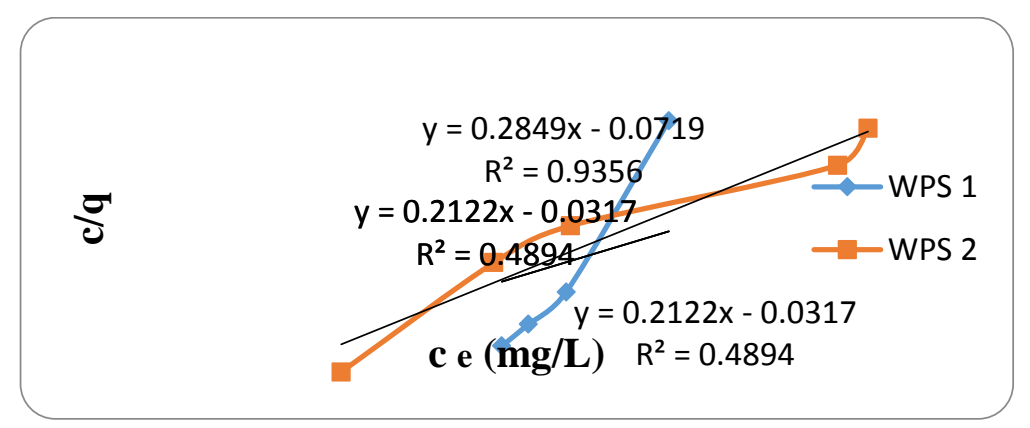

Figure 10. Langmuir isotherms plot for AR adsorption onto Wood white pine sawdust (WPS1 and WPS2) 


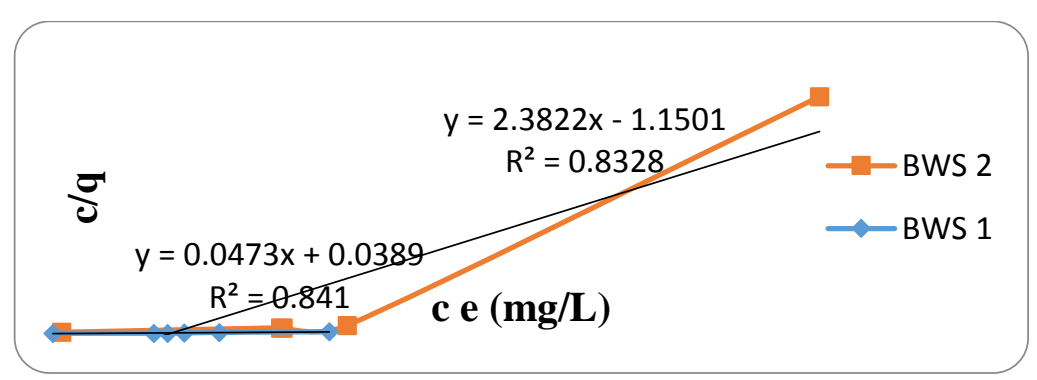

Figure 11. Langmuir isotherms plot for AR adsorption onto Beech wood sawdust (BWS1 and BWS2)

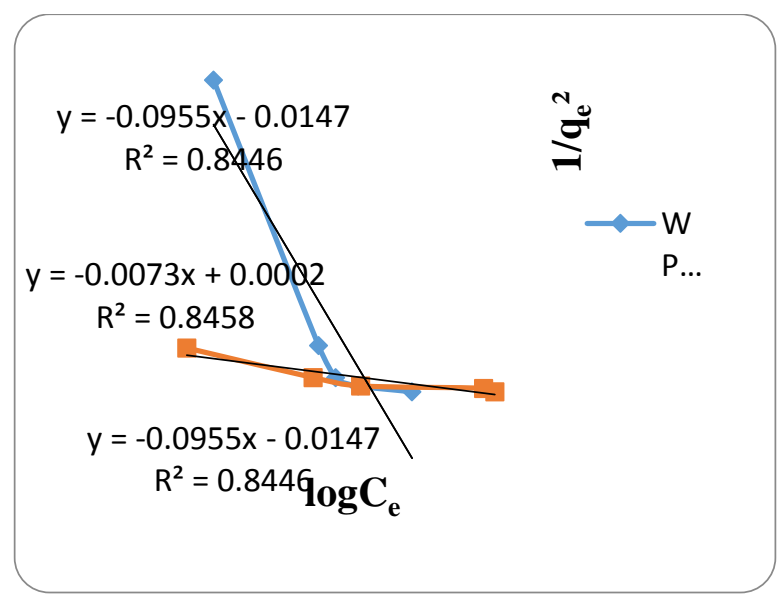

Figure 12. Harkins-Jura isotherm plot for AR adsorption onto Wood white pine sawdust (WPS1, WPS2)

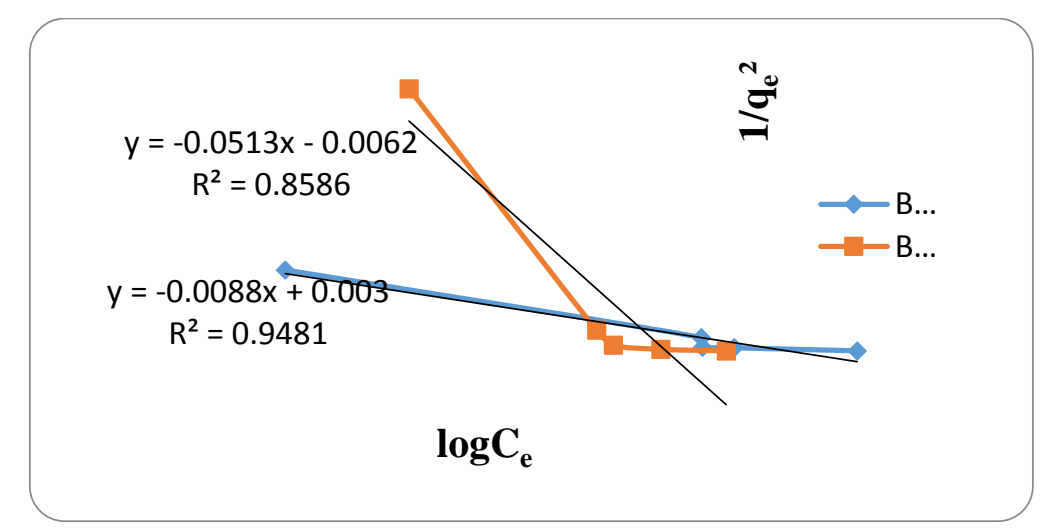

Figure 13. Harkins-Jura isotherm plot for AR adsorption onto Beech wood sawdust (BWS1 and BWS2)

Table 1. Parameters of Freundlich, Langmuir and Harkins-Jura adsorption isotherm models for Alizarin Red S dye removal

\begin{tabular}{|c|c|c|c|}
\hline Sorbent & Langmuir model & Freundlich model & Harkins-Jura model \\
\hline Wood white pine sawdust & $\mathrm{R}^{2}=0,9356$ & $\mathrm{R}^{2}=0,9897$ & $\mathrm{R}^{2}=0,8446$ \\
(Pinus durangensis) & $\mathrm{q}_{\mathrm{m}=3,51 \mathrm{mg} / \mathrm{g}}$ & $\mathrm{K}_{\mathrm{F}}=7,76 \mathrm{mg} / \mathrm{g}$ & $\mathrm{A}_{H J}=10,47$ \\
WPS1 & $\mathrm{K}_{\mathrm{L}=0,2644 \mathrm{~L} / \mathrm{mg}}$ & $\mathrm{n}_{\mathrm{F}}=1,8$ & $\mathrm{~B}_{H J}=1,40$ \\
\hline Wood white pine sawdust & $\Delta \mathrm{G}=+3,29 \mathrm{KJ} / \mathrm{mol}$ & & $\mathrm{R}^{2}=0,8458$ \\
\hline
\end{tabular}




\begin{tabular}{|c|c|c|c|}
\hline (Pinus durangensis) & $\mathrm{q}_{\mathrm{m}}=1,2057 \mathrm{mg} / \mathrm{g}$ & $\mathrm{K}_{\mathrm{F}}=32,97 \mathrm{mg} / \mathrm{g}$ & $\mathrm{A}_{H J}=13,69$ \\
WPS2 & $\mathrm{K}_{\mathrm{L}}=1,7836 \mathrm{~L} / \mathrm{mg}$ & $\mathrm{n}_{\mathrm{F}}=1,7$ & \\
& $\Delta \mathrm{G}=-1,43 \mathrm{KJ} / \mathrm{mol}$ & & $\mathrm{B}_{H J}=1,46$ \\
\hline Beech wood sawdust (Fagus & $\mathrm{R}^{2}=0,841$ & $\mathrm{R}^{2}=0,829$ & $\mathrm{R}^{2}=0,9481$ \\
sylvatica) & $\mathrm{q}_{\mathrm{m}}=21,14 \mathrm{mg} / \mathrm{g}$ & $\mathrm{n}_{H J}=19,49$ \\
BWS1 & $\mathrm{K}_{\mathrm{L}}=1,21 \mathrm{~L} / \mathrm{mg}$ & & $\mathrm{B}_{H J}=3,18$ \\
& $\Delta \mathrm{G}=+0,47 \mathrm{KJ} / \mathrm{mol}$ & & $\mathrm{R}^{2}=0,8586$ \\
\hline Beech wood sawdust (Fagus & $\mathrm{R}^{2}=0,8669$ & $\mathrm{R}^{2}=0,8563$ & $\mathrm{~A}_{H J}=11,36$ \\
sylvatica) & $\mathrm{q}_{\mathrm{m}=0,3780 \mathrm{mg} / \mathrm{g}}$ & $\mathrm{K}_{\mathrm{F}}=16,21 \mathrm{mg} / \mathrm{g}$ & $\mathrm{B}_{H J}=2,6$ \\
& $\mathrm{~K} \mathrm{~L}=1,53 \mathrm{~L} / \mathrm{mg}$ & $\mathrm{nF}_{\mathrm{F}}=1,46$ & \\
\hline
\end{tabular}

A comparison of the isotherms reveals that the correlation coefficients for the Freundlich isotherm were higher and showed better fits for Wood white pine sawdust (Pinus durangensis) WPS1. By comparing the values of $R^{2}$ of the examined isotherm models, it can be concluded that the Freundlich and Langmuir isotherm models gave much better fitting than the Harkins-Jura isotherm model for Wood white pine sawdust (WPS2).This result reveals that dye adsorption onto WPS1 and WPS2 is not support of the multilayer adsorption.

The correlation coefficient for the Langmuir isotherm was higher and showed better fits for Beech wood sawdust (BWS2) and the correlation coefficient for the Harkins-Jura adsorption isotherm presented the best fit for Beech wood sawdust ( $B W S$ 1). This isotherm accounts for multilayer adsorption. The theory proposed by Jura and Harkins states that two phases of the film on the surface exist. [15 - 17] Two straight lines correspond to two different orientations of the adsorptive molecules: the greater slope corresponding to a flat orientation and the smaller slope to a near vertical orientation. [17] Flat orientation is typical for adsorbates which have higher intermolecular attraction, causing them to pack horizontally in the adsorbed layer and it corresponds to higher adsorption capacity and efficiency. [17]

Table 1 shows also that Wood white pine sawdust (WPS1 and WPS2) exhibited greater adsorption capacities than those of Beech wood sawdust (BWS1 and BWS2) adsorbent.

The Freundlich isotherm constant can be used to explore the favourability of adsorption process. The adsorption process is favourable when the value of $n_{F}$ satisfies the condition $1<n_{F}<10$, otherwise it is unfavourable. [9]

\section{Conclusions}

The use of white pine sawdust (Pinus durangensis) and beech wood sawdust (Fagus sylvatica) for the removal of Alizarin Red S dye (AR) from aqueous solutions was investigated.

The effect of various parameters such as dye concentration, $p \mathrm{H}$, adsorbent dose and temperature was studied.

Due to a low cost and a good uptake capacity, the solid waste studied in this research is a promising biosorbent material. The use of non-conventional, low-cost biosorbents can not only reduce a large quantity of solid waste but also be very attractive. Their benefits are mentioned, including low investment cost, simplicity of operation and a remarkable performance even with very low concentration solutions.

The present research demonstrates that white pine sawdust (Pinus durangensis) and beech wood sawdust (Fagus sylvatica), which are abundantly available but generally discarded as agricultural waste are capable of adsorbing dyes and the treatment of such pollutants is expected to be economical.

\section{References}

1.SUTEU, D., ZAHARIA, C., Chemical Bulletin of "Politehnica" University of Timisoara, Romania, Series of Chemistry and Environmental Engineering, 56(70), 2, 2011, p.85-88

2.ATA, S., HAMID, W., RUKH, S., HAMID, S., SYED, A., DIN, I., MOHSIN,I., Turkish Journal of Biochemistry, 37 (3), 2012, p.272-279 
3.SALAZAR-RABAGO, J., RAMOS,R., UTRILLA, J. OCAMPO-PEREZ,R., CERINO-CORDOVA, F., Sustainable Environment Research 27, 2017, p.32-40

4.TRAN, V., NGO, H., GUO,W., ZHANG, J., LIANG, S., TON-THAT, C., ZHANG, X., Bioresource Technology, 182, 2015, p.353-363

5.LEROUX-BERGER M., QUEGUINER, I., MACIEL,T., HO, A., RELAIX, F., KEMPF, H., Journal of Bone and Mineral Research 26, 2011, p.1543-1543

6. SUJITHA, R., RAVINDHRANATH, K., Der Pharma Chemica, 8(9), 2016, p.63-73

7. JACOB, J. S., ROBERTO L.-R., JOSE RIVERA-UTRILLA, OCAMPO-PERE, R., CERINOCORDOVA,F., Sustainable Environment Research 27, 2017, p. 32-40

8. ROUQUEROL, J., ROUQUEROL, F., SING KSW, LLEWELLYN, P., MAURIN, G. Adsorption by Powders and Porous Solids: Principles, Methodology and Applications, 2nd ed. London, UK Academic Press; 2014

9. SARUCHI, S., KUMAR, V. Arabian Journal of Chemistry 2016, article in press, http://dx.doi.org/10.1016/j.arabjc.2016.11.00

10. SUBRAMANI, S.E., THINAKARAN, N., Process Safety and Environmental Protection 106, 2017, p. $1-10$

11. AUTA, M., HAMEED, B.H., Chem. Eng. J. 175, 2011, p.233-243

12. HAMEED, K.S., MUTHIRULAN, P., MEENAKSHI, S.M., Arabian J. Chem 10, 2017, p.22252233

13. MALIK, R., RAMTEKE, D.S., WATE, S.R., Waste Management, 2007, 27, p.1129-1138

14. PAUL S. A., CHAVAN S. K., Oriental Jr. Chem., 2011, 27:4

15. LI, P., SU, Y., WANG, Y., LIU, B., SUN, L.M., Journal of Hazardous Materials, 179, 2010, p.4347

16. SINGHA, B., DAS, S.K, Colloids and Surfaces B, 107, 2013, p.97-106.

17. SHANAVAS, S., SALAHUDDIN KUNJU, A., VARGHESE, H.T., PANICKER, C.Y., Orient. J. Chem. 27 (1), 2011, p. 245-252

Manuscript received: 2.08 .2019 